\title{
Transformation of Phomopsis viticola with the Green Fluorescent Protein
}

\author{
D. J. Anco', S. Kim², T. K. Mitchell'2, L. V. Madden', and M. A. Ellis'.
}

${ }^{1}$ The Ohio Agricultural Research and Development Center, Department of Plant Pathology, 1680 Madison Ave., Wooster, Ohio 44691. 2The Ohio State University, Department of Plant Pathology, 201 Kottman Hall, 2021 Coffey Rd., Columbus, Ohio 43210.

\section{Abstract}

Phomopsis viticola is the causal agent of Phomopsis cane and leaf spot on Vitis spp., which is a serious and economically important disease in temperate regions. Here we describe the transformation of this fungus with two different constructs ( $\mathrm{pBHt}$ 2_sGFP and pIGPAPA) containing the green fluorescent protein (GFP) and the hygromycin $B$ resistance gene $(h p h)$. Protoplast mediated transformation yielded three fluorescent transformants (DA-2, DA-4, and DA-5) and multiple non-fluorescent transformants. All transformants obtained were mitotically stable. The growth rates of DA-4 and DA-5 were slightly, but significantly $(P<$ 0.05 ), less than $\mathrm{DA}-2$ and $\mathrm{OH}-22$ (wild type); however, transformation resulted in no change in sporulation rate, log spore production, and virulence on grape internodes and leaves compared to the wild type. These transformants will be useful tools for elucidating fungal penetration of host plants, invasive growth, and the nature of its host association.
Transformation. Protoplast-mediated transformation was adapted from De Guido et al (2). Protoplast transformation was performed on ice using Hindlll digested plasmids and polyethylene glycol 3350 (PEG).

Protoplast recovery. Transformed protoplasts were recovered in SHV (0.6 M sucrose, $5 \mathrm{mM}$ HEPES $1 \mathrm{mM}$ $\left(\mathrm{NH}_{4}\right) 2 \mathrm{HPO}_{4}, 0.2 \mathrm{mM}$ biotin, and $1 \mathrm{mM}$ thiamine, $\mathrm{pH}$ 5.3) and selected for with hygromycin $\mathrm{B}$. Eight days later, transformed colonies were isolated. Figure 1 compares fluorescent transformants against the wild type (Nikon 80i).

\section{Introduction}

Phomopsis viticola (Sacc.) Sacc. is the causal agent of Phomopsis cane and leaf spot on Vitis spp. This disease occurs worldwide, with the greatest economic losses experienced in moist temperate regions where it can reduce yields by as much as 30\% (4, Ellis, unpublished data). P. Figure 1. Epifluorescence micrographs of viticola can produce necrotic lesions on leaves, internodes, and rachises, as well as rot berries (5). The histological detail of such infections is limited at best.

Reporter genes like the green fluorescent protein (GFP) allow for the visualization of fungal structures upon and within infected tissues. Here we used two GFP containing constructs, each with a different promoter, to transform $P$. viticola.

The successful GFP transformation of $P$. viticola reported here will provide the necessary tools for investigating host penetration, invasive growth, and reproduction by this important pathogen of grapes as well as defining the nature of the hostpathogen interaction.

\section{Materials and Methods}

Fungal strains and plasmids. $P$. viticola wild type strains $\mathrm{OH}-22, \mathrm{OH}-9$, $\mathrm{MI}-2$, and Pv08001 were used in these studies. $\mathrm{OH}-22$ was used for transformation, as it is fast growing and virulent. Transformation plasmids pBHt2_sGFP and pIGPAPA contain the GFP gene driven by the ToxA and ICL promoters respectively, as well as the hygromycin resistance gene (hph) driven by the trpC promoter.
Transformants vs. wild type. Growth rate, time to sporulate, and amount of spores produced after a fixed time were examined. Pathogenicity and virulence were examined on 'Seyval' grapes. Disease severity was measured $14 \mathrm{~d}$ after inoculation on canes (1) and on leaves (4) (Figure 2). Isolations were made from lesion margins on infected leaves and internodes.

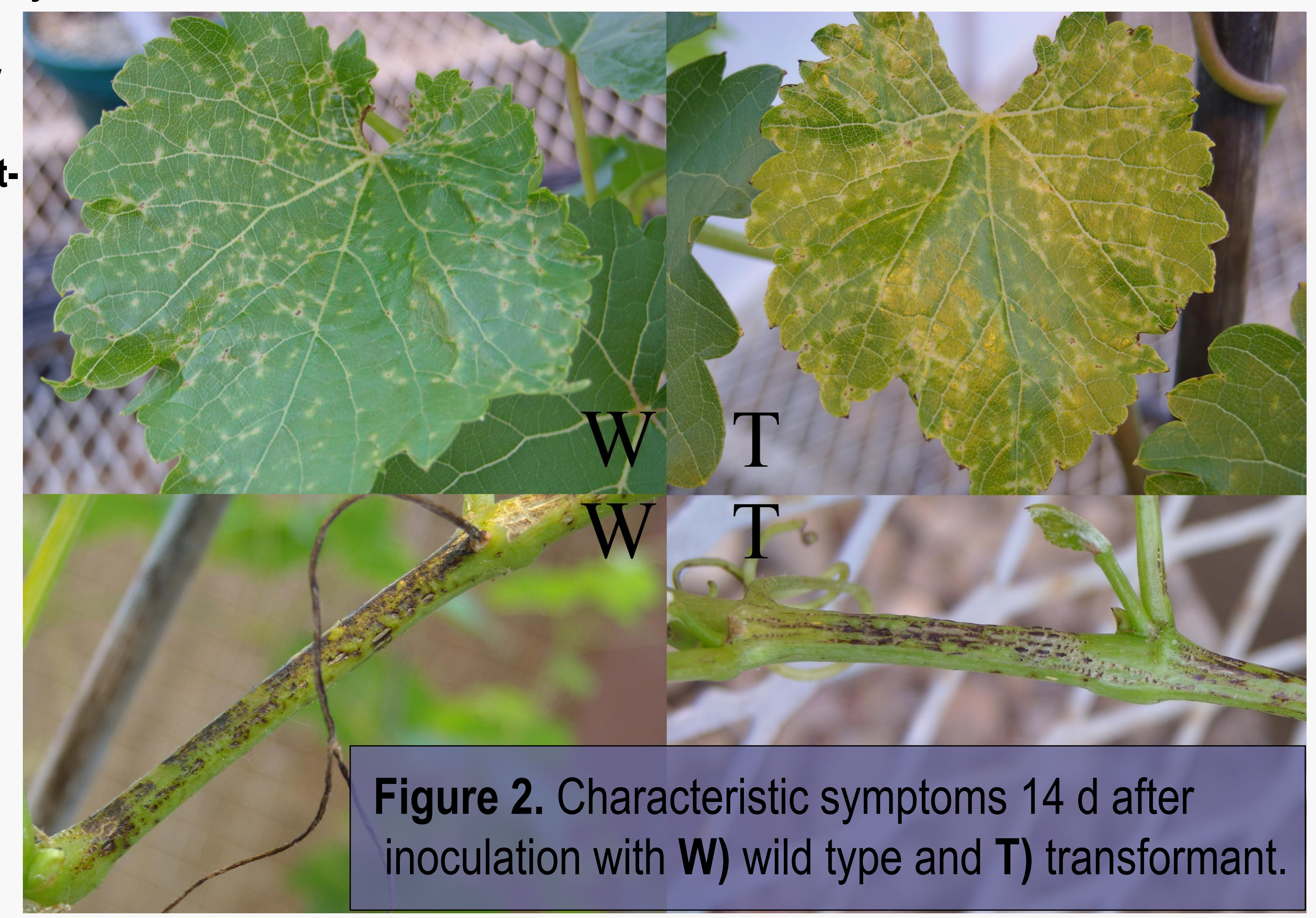


Visualization in grape. 'Seyval' grapes were inoculated with the transformants. Multiple tissues were examined after different times. Figure 3 presents confocal laser scanning micrographs of these examinations (Leica TCS NT).

\section{Results}

Transformation. pBHt2_sGFP transformation yielded 4 hygromycin $B$ resistant colonies (DA-1 through 4). Transformation with pIGPAPA yielded 3 hygromycin $B$ resistant colonies (DA-5 through 8). Three transformants were GFP positive (DA-2, DA-4, and DA-5); Figure 1 shows them compared to the wild type $\mathrm{OH}-22$.

Growth and sporulation of transformants. Growth and sporulation of all strains did not statistically differ. The exception was the second repetition for growth: $\mathrm{OH}$ 22 and DA-2 grew significantly more than DA-4 and DA-5 $(P<0.05$, Tukey's pairwise). None of the strains produced $\beta$-conidia after $14 \mathrm{~d}$ of growth on potato dextrose agar (PDA).

\section{Virulence of transformants. All} strains produced characteristic Phomopsis cane and leaf spot symptoms simultaneously (Figure 2). There was no measurable difference in leaf lesions. Internode disease severity of the transformants was not significantly different from the wild type (Kruskal-Wallis test, $P \geq 0.15$ ). To confirm Koch's postulates, all four $P$. viticola strains used for virulence testing were re-isolated from infected tissues. Transformants were confirmed GFP positive.

Visualization in grape. Fluorescent hyphae of transformants were observed on rachis tissue and within leaf, berry, and internodal tissues (Figure 3). Transformants were observed after short $(1-3 d)$, intermediate $(46-51 d)$, and long (>200 d) time periods after inoculation.

\section{Conclusions and Discussion}

1. The transformation efficiency ( 1 fluorescent transformant per 5 and $40 \mu \mathrm{g}$ of pBHt2_sGFP and pIGPAPA, respectively) in this study was less than the lowest reported by De Guido et al (2) (5-10 transformants $\mu g^{-1}$ of pAN7-1 DNA).

2. De Guido et al used REMI (restriction enzymemediated integration) to increase the number of transformants recovered. This technique has been shown to induce large genome rearrangements in some fungi. We ventured to use a more standard and potentially more stable transformation approach.

3. The growth of DA-4 and DA- 5 was statistically less than DA-2 and $\mathrm{OH}-22$ in one repetition; however, the growth, sporulation rate, log spore production, and virulence of all three transformants are statistically and phenotypically indistinguishable to $\mathrm{OH}-22$.
4. We also demonstrated that the transformants retain their production of GFP during infection of grape. This, in combination with the retention of wild type characteristics, provides confidence these transformants will be useful tools in investigating host penetration, invasive growth, and reproduction by this important pathogen of grapes as well as defining the nature of the host-pathogen interaction.

\section{Acknowledgements and References}

The transformations were made possible with the technical guidance of Dr. Soonok Kim of The Ohio State University. We would also like to acknowledge the assistance of Mr. Lee Wilson and the MCIC staff at the OARDC. Funding was provided by the 2008 Viticulture East Consortium Grant.

1. Barratt, RW, Horsfall, JG. 1945. An improved grading system for measuring plant disease. Phytopathol 35:655.

2. De Guido, MA, Pollastro, S, Carlucci, A, De Miccolis Angelini, RM, Faretra, F. 2003. Phomopsis viticola is easily transformed with $h p h$ and Bm/r genes. J Plant Pathol 85:43-52.

3. Eichorn, KW, Lorenz, DH. 1977. Phänologishche Enwicklungsstadien der Rebe. Nachrbl Dtsch. Pflanzenschutzd. (Braunschweig) 29:119-120.

4. Erincik, O, Madden, LV, Ferree, DC, Ellis, MA. 2001. Effect of growth stage on susceptibility of grape berry and rachis tissues to infection by Phomopsis viticola. Plant Dis 85:517-520.

5. Hewitt, W. B., and Pearson, R. C. 1988. In: Pearson R. C. and Goheen, A. (eds) Compendium of Grape Diseases. The American Phytopathological Society Press. St. Paul, MN. pp. 17-18.

6. Nita, M., Ellis, M. A., Wilson, L. L., and Madden, L. V. 2006. Effects of application of fungicide during the dormant period on Phomopsis cane and leaf spot of grape disease intensity and inoculum production. Plant Dis 90:1195-1200. 